\title{
LA EXCLUSIÓN SOCIAL EN EL MARCO DE LA COMUNICACIÓN PARA EL DESARROLLO Y EL CAMBIO SOCIAL. UN ANÁLISIS DEL TRATAMIENTO DE LA INCLUSIÓN SOCIAL EN CAMPAÑAS DE SERVICIO PÚBLICO SIN ÁNIMO DE LUCRO
}

Social Exclusion in the Frame of Communication for Development and for Social Change. A Study of the Treatment of Social Inclusion in Public Service Non Profit Campaigns

\section{A exclusão social no marco da comunicação para o desenvolvimento e a mudança social. Uma análise do tratamento da inclusão social em campanhas de serviço público sem fins lucrativos}

Alvarado, María. Universidad de Valladolid (España) cruzalop@yahoo.es

De Andrés, Susana. Universidad de Valladolid (España) deandresdelcampo@gmail.com

Collado, Rocío. Universidad de Valladolid (España) rcolladoalonso@gmail.com 


\section{DISERTACIONES}

ESTUDIOS

Anuario electrónico de estudios en Comunicación Social

ISSN: 1856-9536

Doi: dx.doi.org/10.12804/revistas.urosario.edu.co/disertaciones/a.4554

Volumen 10, Número 1/ Enero-junio 2017

Versión PDF para imprimir desde

http://revistas.urosario.edu.co/index.php/disertaciones

Fecha de recibido: 4 de febrero de 2016

Fecha de aceptado: 1 de abril de 2016

\section{RESUMEN}

Este trabajo pretende ubicar el concepto de comunicación inclusiva en el marco de la comunicación para el desarrollo y el cambio social. Se recogen y analizan las referencias a la inclusión social en los textos fundacionales de la comunicación para el cambio social. Se plantean las implicaciones del concepto de comunicación inclusiva y se aportan ejemplos en el ámbito de la comunicación publicitaria social. Se presentan los resultados de un análisis sobre el tratamiento de la inclusión-exclusión social en 91 anuncios gráficos. Como conclusiones, se muestra la escasa importancia que la inclusión social tiene en el ideario de los documentos programáticos de la comunicación para el desarrollo y el cambio social. Se comprueba el liderazgo de las ONG como emisores y la hegemonía noroccidental en la producción del discurso solidario. Se demuestra la exclusión discursiva sobre la propia exclusión social tanto en la programática como en la praxis de la comunicación para el cambio social. Se demuestra la escasa representación visual y verbal de las personas en situación de exclusión social en el conjunto de las campañas con fines solidarios. Se destaca el enfoque basado en el problema y el discurso moral como estrategia de implicación de los públicos.

Palabras clave: inclusión, exclusión, comunicación, publicidad, cambio social.

\section{ABSTRACT}

This paper focuses on situate the concept of inclusive communication in the frame of the communication for development and for social change. References to social inclusion of the founding texts of these theories are collected and analyzed. We reflect on the implications of the concept of inclusive communication, contributing with examples in the particular area of the social advertising communication. The results of the analysis on presence and treatment of social inclusion/exclusion are presented, over a sample of 91 graphic advertisements. As main conclusions, we noted the little relevance of social inclusion in the thinking of the program documents of communication for development and for social change: the leadership of NGOs as issuers of these campaigns, and the north-western hegemony in the production of solidary speech. There is a "discursive exclusion" of the social exclusion topic, both in theory and in practice of communication for social change. So, the poor visual and verbal representation of people in social exclusion in the whole of campaigns with solidarity purposes, is evidenced. It stands out the approach based on the problem rather than the solution, and the use of moral discourse as a strategy to involve the audience.

Keywords: inclusion, exclusion, communication, advertising, social change.

\section{RESUMO}

Este trabalho pretende situar o conceito de comunicação inclusiva no marco da comunicação para o desenvolvimento e a mudança social. Recolhem-se e analisam as referências à inclusão social nos textos fundacionais 


\section{DISERTACIONES}

ESTUDIOS

Anuario electrónico de estudios en Comunicación Social

ISSN: 1856-9536

Doi: dx.doi.org/10.12804/revistas.urosario.edu.co/disertaciones/a.4554

Volumen 10, Número 1 / Enero-junio 2017

Versión PDF para imprimir desde

http://revistas.urosario.edu.co/index.php/disertaciones

da comunicação para a mudança social. Se apresentam as implicações do conceito de comunicação inclusiva, aportando exemplos no âmbito da comunicação publicitária social. Se apresentam os resultados de uma análise sobre o tratamento da inclusão/exclusão social em 91 anúncios gráficos. Como conclusões, se mostra a escassa importância que a inclusão social tem no ideário dos documentos programáticos da comunicação para o desenvolvimento e a mudança social. Comprova-se a liderança das ONGs como emissores e a hegemonia noroeste na produção do discurso solidário. Se constata a exclusão discursiva sobre a própria exclusão social tanto na programática como na práxis da comunicação para a mudança social. Comprova-se a escassa representação visual e verbal das pessoas em situação de exclusão social no conjunto das campanhas com fins solidários. Destaca o enfoque baseado no problema, e o discurso moral como estratégia de implicação dos públicos.

Palavras-chave: Inclusão, exclusão, comunicação, publicidade, mudança social

\section{Introducción}

El sistema de la comunicación (en especial el publicitario) ha generado uno de los principales procesos de globalización, con implicaciones radicales, tanto en el ámbito simbólico, como en el material. Este proceso ha sido connivente con el del capitalismo, un modelo insostenible de crecimiento y expansión comercial. Si bien este proceso continúa, en las últimas décadas se suceden las orientaciones sociales que abren perspectivas a una comunicación menos devastadora, o incluso, promotora de derechos sociales y divulgadora de representaciones igualitarias.

Este trabajo persigue colocar el concepto de comunicación inclusiva en el marco, polémico pero revelador, de los conceptos de comunicación para el desarrollo, comunicación comunitaria, comunicación para el cambio social o comunicación con fines sociales; etiquetas todas ellas que conviven al día de hoy con sus matices diferenciales, que en algún caso afectan de forma directa el papel de la publicidad, en un contexto cada día más demandado. Se plantean aquí las implicaciones del concepto de comunicación inclusiva, aportando ejemplos del particular ámbito de la comunicación publicitaria social de producción occidental.

El presente estudio toma la hipótesis de la escasa atención que recibe la cuestión de la exclusión social en la comunicación para el cambio social. Se presentan los resultados de un análisis sobre el tratamiento que la inclusión/exclusión social ha recibido en los documentos programáticos de la comunicación para el cambio social, así como la representación que recibe en las campañas solidarias, tomando para ello una muestra internacional de publicidad. El estudio presentado se basa en el enfoque de la teoría del discurso, en tanto conjunto de dimensiones de la interfaz entre cognición y sociedad (Van Dijk, 2002). La teoría crítica del discurso destaca la importancia de instituciones, prácticas, conocimientos, etc. para entender el sinuoso proceso de la mutua construcción de la realidad discursiva y la realidad social. La publicidad, entendida como institución social, práctica y lenguaje social dominante (Caro, 2007) aporta el marco de análisis discursivo en el cual se gestiona la inclusión/exclusión. 


\section{DISERTACIONES}

ESTUDIOS

\section{Estado de la cuestión: estudios y conceptos de exclusión social y de publicidad inclusiva}

Este trabajo se enfoca en el análisis de la comunicación para el cambio social en la cuestión de la inclusión/exclusión social. Ha sido ya marcado el potencial descriptivo y la riqueza teórico-analítica de la noción de exclusión social (Byrne, 2002 y Subirats, 2005); y la inclusión se ha definido como pieza clave del Estado del Bienestar del siglo XXI (Silver, 1994 y Romm, 1999).

Para abordar el concepto de inclusión social ha de tenerse en cuenta su polaridad. La mayoría de la literatura se basa en el polo negativo del problema -la exclusión-y no en el positivo de la inclusión. No obstante, Subirats (2005) advierte que no puede definirse la situación de exclusión en términos binarios (estar o no excluido) sino como un proceso multidimensional en el que se producen desplazamientos en la matriz de los diversos aspectos estructurales de la exclusión/inclusión. El concepto de exclusión social es de utilización reciente en ciencias sociales y se inicia con la política social francesa hacia los años setenta con el informe René Lenoir ${ }^{1}$ en 1974 (Lafuente y Faura, 2012 y Bueno, 2000). El concepto se fue institucionalizando, en realidad como un eufemismo para no mencionar el término de pobreza en los países europeos. Una revisión de la historia de implementación del concepto en lo político y en la investigación puede encontrarse en el trabajo de Lafuente y Faura (2012). Siguiendo a Subirats (2005) la conceptualización compleja de la exclusión engloba un conjunto de procesos móviles de carácter fluido, que se traslada hacia zonas de vulnerabilidad, con intensidades personales y grupales cambiantes. La agenda de la inclusión se convierte en un eje estructurador de las nuevas políticas del bienestar en el siglo XXI (Subirats, 2005).

El concepto de exclusión social se ha constituido como un descriptor para políticas y trabajos sociales, más que como un concepto generador de teoría (Tezanos, 1999). Vino a sustituir al término marginación, como palabra clave para referirse a los problemas de la desigualdad (Marco, 2000). El análisis de Tezanos (1999) explica la diferencia dialéctica entre pobreza y exclusión social. Pobreza describe un estado, que afecta a individuos, explicado de forma unidimensional como carencias económicas, propio del enfoque de la sociología de la desviación. El término exclusión social define un proceso estructural y multidimensional propio de la sociología del conflicto y de la integración.

Es importante resaltar que, en esa explicación compleja y multicausal de la exclusión social, los medios de comunicación cumplen un papel relevante. Diversos estudios han explicado y descrito la construcción mediática y la representación de las personas en situación de exclusión social desde el concepto de otredad (Hallam y Street, 2000; Ayala 2003; Zebadúa, 2005 y Barranquero, 2008) o desde el de imaginarios sociales (Seveso, 2009). Pero para este estudio es particularmente interesante el concepto propuesto por Herzog (2011) de exclusión discursiva, desde el que entiende la exclusión social como un proceso complejo y gradual de exclusión en la producción discursiva.

1 Secretario de Estado de Acción Social en el gobierno de Chirac. El informe, que llevaba por nombre Les Exclus: un Francais sur dix, reveló que el $10 \%$ de la población francesa estaba excluida. 


\section{DISERTACIONES}

ESTUDIOS

Anuario electrónico de estudios en Comunicación Social

ISSN: 1856-9536

Doi: dx.doi.org/10.12804/revistas.urosario.edu.co/disertaciones/a.4554

Volumen 10, Número 1 / Enero-junio 2017

Versión PDF para imprimir desde

http://revistas.urosario.edu.co/index.php/disertaciones

\section{La publicidad y su relación con la inclusión/exclusión social. ¿Puede la publicidad ser inclusiva?}

La publicidad puede considerarse como un sistema excluyente, en tanto que participa y promociona el modelo postcapitalista dirigido en su mayoría a las clases medias con poder adquisitivo medio-alto. En este modelo, la publicidad comercial se sitúa como un discurso omnipresente del modelo justificativo de exclusiones sociales. La publicidad comercial es regulada por las normas de Derecho Mercantil que, considera como publicidad ilícita a la publicidad "de tono excluyente" o que presente en una situación preminente a una empresa frente a sus competidores cuando no se apoye en hechos ciertos. Es significativo que no se utilice el mismo apelativo para definir a la publicidad que otorga preminencia a unos grupos sociales frente a otros. Pero paralelamente, durante décadas la comunicación publicitaria ha formado parte de manera sistemática de los programas y acciones estratégicas de desarrollo y cambio social, asumiendo objetivos de difusión de información, persuasión para el cambio de actitudes y captación de recursos con los que financiarlos. En este papel instrumental, persuasivo, masivo, impositivo y mercantilizador ha recibido parte de las críticas ejercidas desde los nuevos modelos hacia lo que se entiende como un fracaso del desarrollo.

Lo que pareciera obvio, que la publicidad utilizada en los programas y acciones de cambio social respete consecuentemente el marco de fines para el que trabaja, en la práctica ha resultado ser excepcional. Una paradoja que es fácil de detectar, por ejemplo, en el análisis de la publicidad con fines recaudatorios, utilizada incluso hoy de modo mayoritario por las Organizaciones no Gubernamentales para el Desarrollo (ONGD), dirigida a los ciudadanos de los países occidentales.

Así lo constataba Vanesa Sáiz (2010), cuando, tras analizar 417 mensajes publicitarios de este tipo procedentes de la década 1999-2009, concluía que

la formación discursiva de la solidaridad, pese a presentarse como un discurso transformador del orden social y moral, participa de su fortalecimiento [...] ya que en sus sentidos hegemónicos la solidaridad opera sobre principios de exclusión, asimetrías y desigualdades que la mera apelación a un instinto o a una comunión sentimental no logra superar (p. 602).

Se apunta aquí sobre la posible crisis de este modelo de representación y la incipiente tendencia hacia una temática menos sentimentalista y más denunciativa en relación específicamente con el tema de la inclusión. La publicidad social ha sido mayoritariamente excluyente en las representaciones de las personas y situaciones vinculadas con acciones de cambio social, ya sea en lugares lejanos o próximos a los receptores a los que se dirige, pero ¿es posible una publicidad inclusiva? Creemos que no es solo posible, sino necesaria, y que esta necesidad debe formar parte de la reinvención que la comunicación publicitaria, entendida como sistema e institución social, debe asumir con urgencia dentro de los nuevos modelos que apuntan desde la profesión a una 'postpublicidad' y desde otros ámbitos a una 'nueva publicidad'.

La etiqueta publicidad inclusiva se está ya utilizando desde hace unos años para referirse a distintos contextos de publicidad libre de discriminación y estereotipos. Así lo hemos encontrado en numerosas noticias en Internet en las que se da cuenta de la existencia de foros y debates sobre la necesidad de una publicidad más inclusiva; la 


\section{DISERTACIONES}

ESTUDIOS

Anuario electrónico de estudios en Comunicación Social

ISSN: $1856-9536$

Doi: dx.doi.org/10.12804/revistas.urosario.edu.co/disertaciones/a.4554

Volumen 10, Número 1 / Enero-junio 2017

Versión PDF para imprimir desde

http://revistas.urosario.edu.co/index.php/disertaciones

convocatoria de premios y concursos que la reconocen; o del establecimiento de compromisos por parte de distintas entidades representativas de la publicidad y de la sociedad².

La publicidad para la inclusión social sería el resultado de estructuras, procesos, objetivos y mensajes inclusivos (De Andrés y González, 2012). Una actitud inclusiva de la publicidad enfocaría hacia la diversidad y no hacia la exclusión; hacia la igualdad de derechos, no hacia la homologación de aspectos y situaciones; hacia el reconocimiento de sujetos individuales y colectivos, no hacia su estereotipación; desde un enfoque de participación y corresponsabilidad; $y$ en la senda de la justicia ecosocial y de los derechos fundamentales como fines.

Una comunicación inclusiva, que entronca de este modo con el paradigma emergente de comunicación para la paz que dibujan Nos, Seguí-Cosme y Rivas (2008), debe valerse de la intersubjetividad y de "la inclusión del testigo, del participante, de los auténticos protagonistas (como forma de acercarse a una memoria histórica-colectiva útil, como forma de ir más allá de la objetividad y neutralidad del discurso histórico, sirviéndose de una personalización intersubjetiva a través de la individualización representativa y dialógica)" (p. 14).

\section{Metodología del estudio}

Para abordar la cuestión de la inclusión/exclusión en el marco de la definición de la comunicación para el cambio social se ha considerado necesario realizar una aproximación doble a dos esferas de su manifestación: por un lado la constituida por su corpus fundacional, recogido en los diversos documentos teóricos de los que se deriva, y que marcan su posicionamiento inicial; $y$, por otro, el que se evidencia en los mensajes publicitarios que se derivan de las necesidades comunicacionales de los agentes que constituyen el mapa del cambio social, y que constituyen una manifestación evidente de su hacer en/para el cambio social. De este modo, se ha realizado un vaciado documental de los manifiestos, actas y textos teóricos que han tratado sucesivamente de establecer los principios y ejes que demarcan la comunicación para el cambio social de la comunicación para el desarrollo, generando un rastreo de la consideración que en ellos se hace de la inclusión/exclusión social. Se pretende de esta forma alcanzar un análisis del discurso que enlace aspectos ideológicos y pragmáticos. Se explora así la entretela de los discursos coetáneos (en particular los que son consecuencia de las campañas derivadas de la agenda social) que promueven el cambio en torno a la cuestión de la exclusión social.

El análisis publicitario se ha realizado sobre una muestra de mensajes catalogados como Public service y Non profit, que no pueden ser considerados sintomáticos de la repercusión que el eje de la inclusión tiene (o no) en la realidad comunicacional de este sector, pero que muestran de forma indicial lo que están presentando las campañas más premiadas y distribuidas en los circuitos mainstream de la publicidad global. Para analizarlos, se ha elaborado una matriz ad hoc, tomando como base el método de análisis de contenido clásico y respetando su carácter sistemático, objetivo y cuantitativo susceptible de utilizarse para conocer y evaluar la imagen ofrecida de un grupo social determinado (Wimmer y Dominick, 1996). En nuestro caso el análisis se basa en la detección y recuento de la presencia o ausencia de los índices de la exclusión/inclusión social en los mensajes publicitarios,

2 Así en Argentina, Uruguay, Perú, Colombia, Bolivia, Estados Unidos, Malta, Ecuador, etc. Ver, por ejemplo, los GLADD Media Award de la Gay and Lesbian Alliance Against Defamation, o el acuerdo en Perú para evitar la discriminación racial. 


\section{DISERTACIONES}

ESTUDIOS

Anuario electrónico de estudios en Comunicación Social

ISSN: $1856-9536$

Doi: dx.doi.org/10.12804/revistas.urosario.edu.co/disertaciones/a.4554

Volumen 10, Número 1/ Enero-junio 2017

Versión PDF para imprimir desde

http://revistas.urosario.edu.co/index.php/disertaciones

e integra otras metodologías que permiten una aproximación cualitativa al tema (Ruiz de Olabuénaga, 1999) que creemos necesarias como en el caso de la investigación de la representación en los medios de problemáticas sociales (Igartua y Humanes, 2004). En concreto, se completará el análisis de contenido con el análisis crítico del discurso, basado en la teoría crítica de Van Dijk (2002) antes referida. Esto permitirá estimar cómo la publicidad social, que de manera sistemática se dirige a los ciudadanos del mundo, practica, reproduce o combate la exclusión, por medio de las representaciones que hace de determinados colectivos protagonistas de los diversos escenarios en los que se focaliza la mejora de la sociedad contemporánea.

El proceso de análisis recogió el total de registros de campañas alojadas en el banco Welovead ${ }^{3}$, catalogadas en la categoría genérica de Public Interest y Non Profit, entre enero de 2012 y agosto de 2015. Estas categorías suelen convocarse en los festivales de publicidad, si bien toman diferentes nomenclaturas. Welovead es probablemente el mayor banco digital que compila publicidad premiada en los principales festivales de la industria. Si bien esta publicidad no puede considerarse representativa de las campañas de interés público o sin ánimo de lucro, se trata de un banco de publicidad premiada en diferentes festivales internacionales y locales, lo que le concede a esta muestra un cierto valor prescriptor y una notoriedad elevada como referencia profesional. Si bien no ha de ser la publicidad de mayor incidencia en el público, sí es, probablemente, la publicidad de mayor influencia en el colectivo de profesionales de la publicidad.

Se ha elegido este período para permitir un análisis de actualidad. La muestra fue construida mediante la selección de la gráfica principal de cada campaña. Se excluyeron las campañas ambientales al no referenciar la cuestión de la exclusión social. De un universo total de 1.300 anuncios de Public Service y Non profit encontrados en este periodo, se obtuvieron 91 piezas de publicidad gráfica que referenciarán la cuestión de la exclusión/inclusión social.

Para el análisis, se utilizó una matriz con 42 variables cuantitativas y cada una de ellas se considera un factor de análisis que tiene distintos grados. Las 91 imágenes han quedado caracterizadas por esos factores y por los distintos grados de cada uno de ellos. A partir de las imágenes se ha calculado la frecuencia relativa de cada grado en cada factor. La matriz filtra la identificación de emisores de los mensajes, registra aspectos relativos a las personas representadas y las temáticas sociales que abordan la exclusión social.

La inclusión es un valor, que transita tanto en los objetivos, como en los procesos y los mensajes. Entendida así, la matriz diseñada recoge algunos datos con respecto a los siguientes aspectos:

- Los lugares geográficos, las agencias publicitarias y los anunciantes que están construyendo esas campañas relacionadas con la inclusión/exclusión social. Información sobre la agencia que construye el discurso de la exclusión/inclusión, ya que las raíces de la exclusión son estructura y agencia (Subirats, 2005)

- Los objetivos de las campañas referidas a la exclusión social. Se pretende con ello encontrar los sectores sociales que están insertando la inclusión en la agenda social y produciendo un imaginario al respecto

- Los mensajes que recogen aspectos del abordaje de la representación/mención de las personas o grupos sociales beneficiarios de la campaña solidaria. Entre ellos, analizamos: si están o no presentes, su protagonismo, el tratamiento más o menos victimista que reciben (por medio de imágenes, palabras y gestos) y si se les da nombre y si se les otorga la voz.

3 Recoge campañas premiadas en más de diez festivales internacionales como International ANDY Awards, The One Show, Cannes Lions International Festival of Creativity. También regionales y nacionales como Dubai Lynx Awards, The Creative Circle Awards y British Arrows.

\section{4}




\section{DISERTACIONES}

\section{ESTUDIOS}

Anuario electrónico de estudios en Comunicación Social

ISSN: 1856-9536

Doi: dx.doi.org/10.12804/revistas.urosario.edu.co/disertaciones/a.4554

Volumen 10, Número 1/ Enero-junio 2017

Versión PDF para imprimir desde

http://revistas.urosario.edu.co/index.php/disertaciones

Tabla 1. Presentación de las 42 variables cuantitativas utilizadas en el análisis y sus distintos niveles

\begin{tabular}{|c|c|c|}
\hline Variables & Etiqueta & Valores \\
\hline Número de piezas & FT. NP & Piezas que tiene la campaña gráfica \\
\hline País de producción & FT.PP & Nombre del país \\
\hline $\begin{array}{l}\text { Premios en concursos internacionales } \\
\text { de carácter mundial }\end{array}$ & FT.PIM & Nombre del concurso \\
\hline $\begin{array}{l}\text { Premios en concursos internacionales } \\
\text { de carácter continental }\end{array}$ & FT.PIC & Nombre del concurso \\
\hline Premios en concursos nacionales & FT.PN & Nombre del concurso \\
\hline Año del premio & FT.A & Año \\
\hline Agencia de publicidad & FT.AP & Nombre de la agencia \\
\hline Tema social tratado & FT.TS & $\begin{array}{l}\text { Salud y bienestar social, integración, medio ambiente, } \\
\text { cooperación, catástrofes }\end{array}$ \\
\hline Problema social que plantea & FT.PS & "Libre" \\
\hline Emisor & FT.E & Nombres de los emisores \\
\hline Tipo de emisor & FT.ET & Público, privado, mixto \\
\hline Entidad del emisor & FT.EE & ONG o similar, institución pública, empresa \\
\hline Quién habla a quién & AR.QHQ & Nosotros, vosotros, ellos \\
\hline A quién se da voz & AR.V & Beneficiario, emisor, receptor, realidad \\
\hline Direccionalidad de la comunicación & AR.DC & Unidireccional, bidireccional \\
\hline Elemento de mayor presencia & AR.MP & Emisor, receptor, beneficiario, problema, solución, otros, varios \\
\hline Presencia del emisor & AR.EP & Verbal, visual, ambos \\
\hline Frecuencia de presencia del emisor & AR.EF & Número de veces que aparece el emisor \\
\hline Posición del emisor & AR.EP & Autoridad, experto, mediador, otra \\
\hline Autocita del emisor & AR.EA & Sí, no \\
\hline Presencia del receptor & AR.RP & Verbal, visual, ambos \\
\hline Diálogo con el receptor & AR.RD & Sí, no \\
\hline Petición al receptor & AR.RP & $\begin{array}{l}\text { Conocer el problema, consumir, ayudar, reflexión, toma de } \\
\text { conciencia, empatizar, compromiso, otra acción puntual }\end{array}$ \\
\hline Forma de inducir a la acción & AR.RF & Sentimental o emocional, moral o racional \\
\hline Culpabilización del receptor & AR.RC & Sí, no \\
\hline Actitud hacia la acción solicitada & AR.RA & Egoísta, altruista \\
\hline Rol atribuido al receptor & AR.RR & $\begin{array}{l}\text { Experto-desconocedor, activo-pasivo, donante-ciudadano, } \\
\text { imparcial-comprometido, responsable-no responsable }\end{array}$ \\
\hline Beneficiarios de la acción social & AR.B & "Libre" \\
\hline Presentación de los beneficiarios & AR.BP & Verbal, visual, ambos, no \\
\hline Se da voz a los beneficiarios & AR.BV & Sí, no \\
\hline Discurso de los beneficiarios & AR.BD & De sí mismos, de su problema, piden ayuda, de otros \\
\hline
\end{tabular}




\section{DISERTACIONES}

ESTUDIOS

Anuario electrónico de estudios en Comunicación Social

ISSN: 1856-9536

Doi: dx.doi.org/10.12804/revistas.urosario.edu.co/disertaciones/a.4554

Volumen 10, Número 1 / Enero-junio 2017

Versión PDF para imprimir desde

http://revistas.urosario.edu.co/index.php/disertaciones

\begin{tabular}{|l|l|l|}
\hline \multicolumn{1}{|c|}{ Variables } & Etiqueta & \\
\hline Tipo de beneficiarios & AR.BT & "Libre" \\
\hline Actitud mostrada por los beneficiarios & AR.BA & "Libre" \\
\hline $\begin{array}{l}\text { Gestualidad de los beneficiarios- } \\
\text { mirada }\end{array}$ & AR.BGM & Mirada hacia observador, mirada desviada \\
\hline $\begin{array}{l}\text { Gestualidad de los beneficiarios- } \\
\text { expresión }\end{array}$ & AR.BGE & Felicidad, sorpresa, miedo, disgusto, ira, tristeza, otra \\
\hline $\begin{array}{l}\text { Gestualidad de los beneficiarios- } \\
\text { posición corporal }\end{array}$ & AR.BGC & De frente, de perfil, de espaldas \\
\hline $\begin{array}{l}\text { Gestualidad de los beneficiarios-otros } \\
\text { gestos }\end{array}$ & AR.BGO & Manos tendidas, abrazo, otros \\
\hline $\begin{array}{l}\text { Carácter dependiente de los } \\
\text { beneficiarios }\end{array}$ & AR.BD & Sí, no \\
\hline Protagonismo de los beneficiarios & AR.BP & Sí, no \\
\hline $\begin{array}{l}\text { Integración de los beneficiarios en el } \\
\text { mensaje }\end{array}$ & AR.BI & De manera natural, forzada \\
\hline $\begin{array}{l}\text { Rol de los beneficiarios } \\
\text { Representación estereotipada de los } \\
\text { beneficiarios }\end{array}$ & AR.BE & $\begin{array}{l}\text { Activo-pasivo, responsable-no responsable, víctima-verdugo, } \\
\text { capaz-incapaz de resolverlo, objeto-sujeto, dependientes- } \\
\text { autónomos, tristes-felices }\end{array}$ \\
\hline
\end{tabular}

Fuente: elaboración propia.

\section{Tratamiento de la cuestión de la exclusión/inclusión social en el discurso de la comunicación para el desarrollo y el cambio social}

Las denominaciones de comunicación para el cambio social, para el empoderamiento, y para el desarroIlo, aparecen en un sistema de transferencias (Marí, 2013) entre praxis y debates teóricos e ideológicos, en un proceso que Marí explica en términos de transiciones a múltiples niveles que relacionan movilizaciones, investigaciones, epistemologías del sur; que está generando una institucionalización de esa comunicación: "Diferentes aproximaciones para denominar y caracterizar un campo relacionado con el papel de la comunicación en los esfuerzos estratégicos para superar los problemas sociales colectivos" (p. 42).

Todas esas denominaciones han vivido un auge notable, pero a la vez han acumulado una serie de críticas, que han sido señaladas por los autores de referencia. Como indica Barranquero (2012), heredan la concepción que de esos términos han acuñado organizaciones internacionales como Unesco, Aecid, FAO, BM y Usaid: androcentrismo, instrumentalismo, universalismo, concepción occidental y procedimental del desarrollo; o eurocentrista, en palabras de De Sousa y Meneses (2014); en definitiva, un modelo único de desarrollo, orientado al crecimiento económico.

Comunicación para el cambio social fue una denominación alternativa a la de comunicación para el desarrollo gestada, como indican Navarro (2009) y Gumucio-Dagron (2004), hacia 1997 a partir de los foros convocados por la Fundación Rockefeller, y ratificada luego en el Primer Congreso Mundial de la Comunicación para el Desarrollo 


\section{DISERTACIONES}

ESTUDIOS

Anuario electrónico de estudios en Comunicación Social

ISSN: $1856-9536$

Doi: dx.doi.org/10.12804/revistas.urosario.edu.co/disertaciones/a.4554

Volumen 10, Número 1 / Enero-junio 2017

Versión PDF para imprimir desde

http://revistas.urosario.edu.co/index.php/disertaciones

celebrado en 2006. Pero a pesar del carácter novedoso y alternativo que parecía alumbrar esta nueva etiqueta, puede considerarse también una definición institucionalizada al ser suscrita por organismos como la FAO y el Banco Mundial, que convocaron dicho congreso, además bajo la denominación clásica que se pretendía renovar.

Aunque sí cuestiona las tesis desarrollistas, el problema de esta nueva denominación recae, según autores como Chaparro (2013) y Marí (2013) en el propio término "cambio" que no problematiza, ni tiene orientación marcada, y que admite su utilización por ideologías y posturas teóricas diversas. Para avanzar hacia unos conceptos más comprometidos con el beneficio social, Barranquero (2012) propone la incorporación de fines como la justicia ecosocial y el buen vivir.

En este trabajo - donde remarcamos en la importancia de la inclusión como factor imprescindible para la mejora social, dentro de un marco de fines relacionados con los Derechos Humanos, en el que la comunicación social debe primar-, la pregunta sería: ¿cuál de esas denominaciones o perspectivas es más coherente con una actitud inclusiva? Para ello, hemos revisado los principales documentos institucionalizados de dichas modelizaciones de la comunicación con fines de transformación social. Mediante el buscador informático de palabras se ha realizado un rastreo de la presencia de los términos 'inclusión/exclusión social', y se han encontrado para su análisis los siguientes documentos:

- Communications and Social Change: Forging Strategies for the 21st Century (1997)

- Manifiesto de la conferencia de Cape Town (1998)

- Consortium Brochure. Escuchar... aprender... las voces comunitarias que promueven el cambio. Documento que recoge la misión y visión del Consorcio de la Comunicación para el Cambio Social (CFSC, 2003)

- Gumucio Dragon, Alfonso: haciendo olas: historias de comunicación participativa para el cambio social (Fundación Rockefeller, 2001)

- Conclusiones del Primer Congreso Mundial de la Comunicación para el Desarrollo (The World Bank, 2007)

Se recogen a continuación los resultados obtenidos de esta búsqueda. Si nos remontamos a la primera fase de la institucionalización de este concepto (primeras reuniones en Bellagio, 1997) de las que salieron diversos documentos (Communications and Social Change: Forging Strategies for the 21st Century de abril de 1997 y el Manifiesto de la conferencia de Cape Town en 1998), la comunicación para el cambio social se define como "un proceso de diálogo privado y público, a través del cual los participantes deciden quiénes son, qué quieren y cómo pueden obtenerlo" (Gumucio-Dagron, 2004, p. 22). Una noción bajo la que se planea de manera implícita la necesidad de incluir a las personas en el proceso. El enfoque señala también que "las comunidades deben ser actores de su propio desarrollo, que la comunicación no debe persuadir sino facilitar el diálogo, y que no debe centrarse en los comportamientos individuales sino en las normas sociales, las políticas y la cultura” (Gumucio-Dagron, 2004, p. 22). Considerar que las comunidades deben ser actores de su propio desarrollo supone, al menos, hacerlas partícipes, no excluirlas del mismo, lo que es un avance respecto a la aplicación dominante anterior: modernizadora, vertical, impositiva, persuasiva y exógena. Entre las líneas estratégicas propuestas ya en 1997 para guiar la comunicación para el cambio social del siglo XXI, se recoge una que alude de forma más clara a la inclusión utilizando el tema de la voz y que propone Support People Using heir Own Voices, es decir, apoyar a las personas utilizando sus propias voces (Rockefeller Foundation, 1997).

Una idea que también se recoge en el texto mediante el cual el Consorcio de la Comunicación para el Cambio Social (CFSC) da a conocer su misión y su visión, con el objetivo de mejorar las condiciones de vida de aquellos que 
han sido excluidos durante mucho tiempo afirma: "Nuestro trabajo está basado en un conjunto de principios que incluyen voz y participación para todos; equidad en el acceso a contenidos, medios y canales de comunicación; justicia y tolerancia" (CFSC, 2003, s/p). Esta idea, junto con la que las personas deben transmitir sus historias en su propia voz, está presente en muchas partes del documento.

En otro de los textos fundacionales de este modelo, el recopilatorio de casos titulado Haciendo olas (Gumucio-Dragon, 2001), no se alude explícitamente a la necesidad de incorporar un enfoque inclusivo en la comunicación para el cambio social, pero sí se deja claro que las 50 experiencias recogidas "permiten a la gente que vive en comunidades muy pobres en los cuatro rincones del planeta, tomar en sus manos sus propias historias de vida y comenzar a cambiar las circunstancias de su pobreza, discriminación y exclusión" (Gumucio-Dragon, 2001, p. 1). Se reconoce así el poder de la comunicación para cambiar las situaciones de exclusión, en concreto las relacionadas con la pobreza y la discriminación, lo que no implica necesariamente estar en los parámetros de una comunicación inclusiva.

Por último, en el documento que recoge las conclusiones del Primer Congreso Mundial de la Comunicación para el Desarrollo (The World Bank, 2007) sí se integra la inclusión social como un descriptor señalado, concretamente relacionado con el Sur y la pobreza. El término inclusión se refiere en este caso a las personas marginadas, a las personas con discapacidad y también a la inclusión digital. Cuestión esta no exenta de polémicas sobre todo en lo que se refiere a la paradoja que supone confrontar el mito de la sociedad del conocimiento -sociedad red (extensión, apropiación, ciudadanía, participación, ciberdemocracia de las TIC) - con las políticas restrictivas aplicadas, por ejemplo, en el contexto europeo, tal como señala Sierra (2010): “ [...] excluyendo o marginando del proceso el potencial creativo de la ciudadanía y el tejido social organizado que hacen factible, en la praxis, la apertura creativa de nuevas formas de mediación a través de las tecnologías digitales” (p. 235).

\section{Resultados y análisis. La inclusión/exclusión social en las campañas de interés público y sin ánimo de lucro}

Se está construyendo una agenda del desarrollo y el cambio social que prioriza unos temas frente a otros, y esos temas priorizados generan campañas. De ahí el interés por analizar a la publicidad como filtro y selección de lo que se incluye/excluye en la agenda de las entidades sin fines de lucro. ¿Cuáles son los temas que consiguen mayor atención? La publicidad social se está premiando ya en los festivales internacionales, lo que permite una difusión global de su comunicación. Pero estos festivales inciden sobre todo en los creadores de campañas, al mostrar los caminos aplaudidos de la creatividad. Las campañas premiadas constituyen material de referencia para las agencias de publicidad y los planificadores estratégicos. La construcción del imaginario de la solidaridad se fragua en el proceso creativo en el que las ideas se polinizan ¿Qué tratamiento de los problemas sociales está siendo premiado y aplaudido por los creadores de anuncios? ¿Puede decirse que el discurso de la publicidad social es inclusivo?

Para responder a estas preguntas se extrajo una muestra de estudio tomada de Welovead, que probablemente es el mayor archivo digital de publicidad internacional de libre consulta, y que en el momento de tomar la muestra superaba la cifra de 115.000 anuncios. Es importante aclarar que las campañas seleccionadas de este banco no son representativas de toda la publicidad difundida; su fuente de alimentación son festivales que, si bien tienen apertura internacional, son soportados por los países hegemónicos de la creación publicitaria. La participación en 


\section{DISERTACIONES}

ESTUDIOS

Anuario electrónico de estudios en Comunicación Social

ISSN: $1856-9536$

Doi: dx.doi.org/10.12804/revistas.urosario.edu.co/disertaciones/a.4554

Volumen 10, Número 1 / Enero-junio 2017

Versión PDF para imprimir desde

http://revistas.urosario.edu.co/index.php/disertaciones

los concursos conlleva costes para quienes presentan las piezas, lo que inclina la balanza a favor de las grandes agencias. Sin embargo, Welovead constituye una fuente numerosa, documentada y global de publicidad, donde uno de los principales criterios que se tiene en cuenta para otorgar los premios es la creatividad. El hecho de que sean campañas premiadas dota a esa creatividad de cierto consenso sobre el acierto del enfoque. Además, estos anuncios, cuando son premiados, suelen generar notoriedad a escala global de ONGD y entidades con fines sociales, marcando así tendencias discursivas por esta razón. La muestra constituye una base de calidad en términos de influencia, creatividad, producción y notoriedad internacional.

A continuación ofrecemos un resumen de los resultados obtenidos en esta primera fase que consideramos la más relevante en relación con los objetivos planteados.

\section{Países, sectores y tipos de emisores que más publicidad de interés público realizan}

Al indagar en cuáles son los sectores sociales que están atendiendo la inclusión, aparecen entre los más recurrentes: el sanitario y el de derechos y libertades. En el primero destacan los mensajes sobre enfermedades (terminales, mentales, degenerativas o contagiosas); en el de derechos y libertades, los temas más tratados son la libertad de prensa, el tráfico de personas, el comercio de armas y la igualdad de género.

La mayor producción en este tipo de publicidad premiada se concentra en Europa, con el liderazgo de Francia (12), Reino Unido (8), España (4), Alemania (3) y Bélgica (3). Por su parte, América del Norte concentra el segundo gran bloque de campañas con Canadá (7) y Estados Unidos (7). Destaca la producción de Brasil (8), el único país del Sur con una posición importante en este ranking de potencias creativas relacionadas con el cambio social. En este sentido, se observa la brecha Norte/Sur en la producción del discurso publicitario de lo social. Esta brecha es provocada por la propia dinámica de la industria, que favorece a quien más produce.

Son los grandes grupos internacionales de agencias publicitarias con matriz estadounidense los que acaparan estos premios transnacionalmente, y las convierten en factorías de mensajes. Aunque también es verdad que la hegemonía estadounidense de la publicidad se está equilibrando con el bloque europeo y con los grupos emergentes de Asia-Pacífico, aún sus cuarteles dirigen el modelo discursivo más premiado. En primer lugar aparecen las agencias Leo Burnett y Ogilvy (12 piezas cada una), seguidas de Y\&R (11 piezas).

La mayoría de los emisores son entidades no lucrativas y en particular ONGD (49) y asociaciones, fundaciones o movimientos sociales (36). Por el contrario, son muy escasas las campañas realizadas por instituciones públicas (3) o empresas (3).

\section{Aspectos de la exclusión social representados en las campañas}

La exclusión social puede hacerse presente en los anuncios y representar diferentes aspectos. En este estudio se ha analizado cuál es el aspecto más subrayado acerca de la exclusión social entre las personas beneficiarias, los emisores de la publicidad, el problema, las personas receptoras o destinatarias del anuncio, la solución al problema u otras cuestiones, de las cuales destaca la exposición del problema $(64,84 \%)$ sobre todos los demás. 


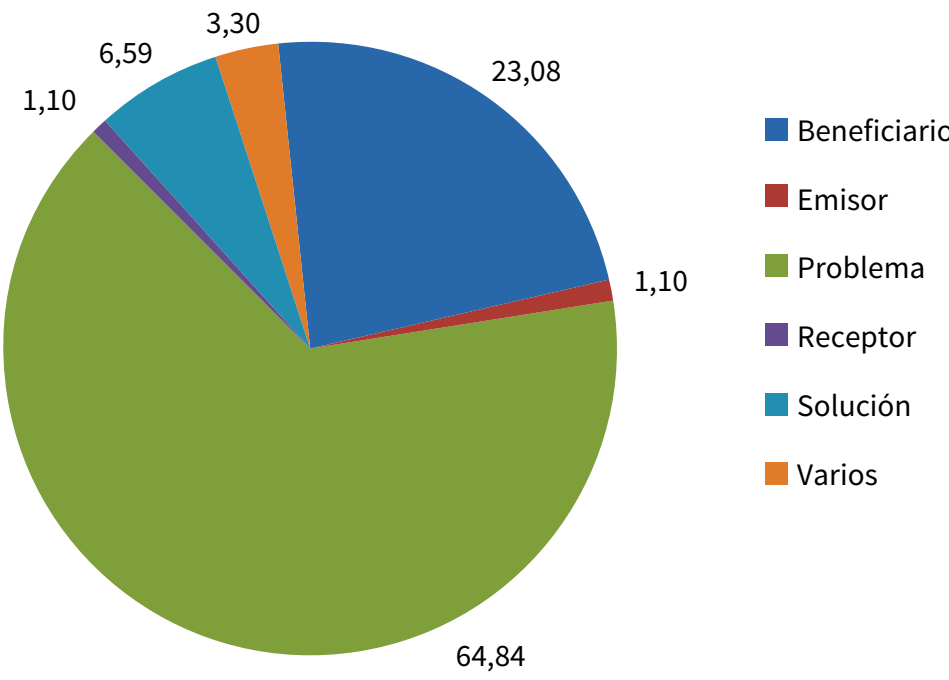

Fuente: elaboración propia.

Sobre la representación de los beneficiarios, esto es, de los grupos o personas en situación de exclusión social, los resultados muestran que aparecen solo en un 23,08\%, y aparecen dominantemente de forma visual (35,56\%) o verbo-visual (34,44\%). En cuanto al tratamiento/rol que se les asigna destaca la categoría de "víctimas" (34) seguida de "ciudadanos" (25). En un $71,11 \%$ de las veces no se les da voz. Cuando se hace, su voz habla del problema (19) o de sí mismos (6) y solo en un caso de la solución.

Otro de los aspectos analizados en esta investigación indaga por la aproximación moral hacia las personas receptoras de los mensajes publicitarios, y analiza el mecanismo persuasivo de la culpabilización. Encontramos que el receptor de los mensajes es culpabilizado en un $23 \%$ de las ocasiones. Esta estrategia de aproximación, si bien puede llamar a la responsabilidad de todos y todas en los problemas sociales, condiciona una aproximación discursiva negativa. El supuesto salvador, a quien las campañas definen como público objetivo, es presentado como culpable. Utilizando la culpa, el enfoque adquiere un tratamiento moral y busca una movilización desde las emociones negativas.

Tabla 2. Número de campañas encontradas con tratamiento de culpabilización al destinatario de los mensajes

\begin{tabular}{|c|c|c|}
\hline Culpabilización del receptor & $n^{\circ}$ & $\%$ \\
\hline Sí & 21 & 23,08 \\
\hline No & 70 & 76,92 \\
\hline Total & 91 & 100 \\
\hline
\end{tabular}

Fuente: elaboración propia. 


\section{Discusión y conclusiones}

Revisados los documentos de definición de la comunicación para el desarrollo y para el cambio social, no parece que más allá de los principios de horizontalidad, participación, diálogo y apropiación la inclusión social sea una prioridad. Incluso si aceptamos como tal la misión de "mejorar las condiciones de vida de aquellos que han sido excluidos..." encontramos un tratamiento escaso y restringido (mejorar esas condiciones no significa necesariamente incluir a las personas). Está, pues, por ampliar y desarrollar una definición de comunicación para el cambio social que considere y visibilice la inclusión social.

A partir de la investigación en la muestra seleccionada de los mensajes publicitarios de servicio público, se avanza en evidencias de cómo los grupos o personas desfavorecidas a quienes pretenden beneficiar las campañas más aplaudidas de ONGD y entidades sin ánimo de lucro, apenas son dotados de voz (17 casos) y visibilidad en los mensajes (23,08\%).

En las campañas analizadas se encuentra que se está reproduciendo un discurso publicitario en el que los grupos o personas desfavorecidas obtienen una inclusión visual o icónica escasa, presentados mayoritariamente en el papel de víctimas (61,64\% de los casos en los que aparecen) y sin voz. El discurso de la publicidad social plantea en un porcentaje elevado de casos una dialéctica de víctimas (personas en situación de exclusión) y culpables (receptores). La otra estrategia dominante es la dialéctica del fantasma del problema (64,84\%) que invisibiliza el eje de soluciones, ya que receptor, emisor y solución no adquieren protagonismo en los mensajes.

Desde un enfoque básico de desarrollo, parece que queda mucho hacia un giro discursivo que logre presentar participantes (no víctimas pasivas), en un enfoque enunciativo, denunciativo y asertivo. Se confirma la presencia de un imaginario perverso (Chaparro, 2013) en la comunicación para el cambio social. En este tapiz, el discurso encontrado no habla de cambio social sino de problemas sociales.

El modelo discursivo de las campañas solidarias analizadas no está fomentando la creación de un imaginario acorde con los principios de participación de la comunicación para el cambio social, en el que las comunidades son partícipes y principales agentes de su desarrollo. En este imaginario de personas desfavorecidas sin voz, lo que se construye es un sistema de ayuda distorsionado y opresivo. En un planteamiento dicotomizado de problema/ solución, exclusión/inclusión, la comunicación de las entidades solidarias refuerza el polo discursivo negativo.

Este modelo de imágenes negativas que buscan lanzar un mensaje de culpa para recaudar fondos pertenece al discurso de la caridad más que a un modelo de solidaridad (dar y tomar). Esto evidencia la escasa repercusión que tienen en el discurso de la publicidad, entendido como último eslabón de la cadena, pero como el más visible por el ciudadano de a pie, las directrices establecidas en los documentos fundacionales de la comunicación para el desarrollo y el cambio social. Esto puede deberse, ya sea a la mínima repercusión que estos tienen en las estrategias de los emisores públicos o privados que lo acaparan, o por la dificultad que existe para materializar el giro comunicativo esperado, en un sistema que, como el publicitario, es por excelencia conformista y conservador. Se avanza así en la hipótesis expuesta por Aquilina Fueyo de la domesticación del discurso social, entendiendo por ello "[...] la asunción completa por parte de un individuo o un grupo, de los elementos de las representaciones sociales ligadas a los intereses de los grupos sociales dominantes (incluyendo los factores ideológicos y las prácticas sociales de ellos derivadas" (Fueyo, 2002, p. 204). La invisibilización de las personas excluidas merma el 


\section{DISERTACIONES}

ESTUDIOS

Anuario electrónico de estudios en Comunicación Social ISSN: 1856-9536

Doi: dx.doi.org/10.12804/revistas.urosario.edu.co/disertaciones/a.4554

Volumen 10, Número 1/ Enero-junio 2017

Versión PDF para imprimir desde

http://revistas.urosario.edu.co/index.php/disertaciones

impacto de las imágenes testimoniales que relatan la realidad de la desigualdad social. Esta evitación de la representación del eje de soluciones, entendemos, es una forma de resistencia y debilitamiento en sí misma, que hace de los escenarios de la exclusión social un cliché más, y actúa como vacuna de nuestra capacidad resolutiva en la ayuda humanitaria, colaboración y empatía social.

Somos conscientes de que el corpus estudiado deja por fuera del análisis la publicidad de ONGD y otros movimientos sociales cuyas campañas no se distribuyen en esta base de datos y que podrían estar utilizando otros enfoques en el tratamiento de las temáticas sociales. Así sucede, por ejemplo, con los videos premiados en otros festivales más especializados, como sería el caso de la fundación SAIH (The Norwegian Students and Academics International Assistance Fund), con The Radiator Awards, en los que se premian, desde 2013 y de forma anual, los mejores y peores videos, según ofrezcan una visión más o menos estereotipada de África. Sin embargo, y si bien es significativo que estén surgiendo este tipo de iniciativas que ponen el foco en la necesidad de un cambio de discurso en las campañas sociales, para esta primera aproximación hemos considerado oportuno estudiar la publicidad 'tradicional' que acude a los grandes festivales y que, además de permitirnos estudiar un amplio espectro de temáticas, todavía hoy es la mayoritaria.

Los mensajes publicitarios pueden ser síntomas y acicate del avance o retroceso de un sistema, en este caso, el que genera la permanente necesidad de cambio y mejora social. Es posible que, al analizar los ejes de exclusión que la publicidad representa, se pueda elaborar una propuesta que permita asentar las bases de una comunicación de transformación social comprometida, responsable y necesariamente inclusiva.

\section{Referencias}

1. Ayala, G. (junio, 2003). Medios de comunicación: constructores de discursos que polarizan y desdibujan la otredad. Diálogos de la comunicación, (66), 81-90.

2. Barranquero, A. (2008). La comprensión de la otredad desde la comunicación para el cambio social y el diálogo. En R. Pérez-Amat., S. Núñez y A. García. (eds.) Comunicación, identidad y género. (pp. 239-247). Madrid: Fragua.

3. Barranquero, A. (abril, 2012). De la comunicación para el desarrollo a la justicia ecosocial y el buen vivir. Cuadernos de información y comunicación, (17). Recuperado de http://goo.gl/UBnui3

4. Bueno, J. (abril, 2000). Concepto de representaciones sociales y exclusión. Acciones e investigaciones sociales, (11), 23-48.

5. Byrne, D. (2002). Social Exclusion. Buckingham: Open University Press.

6. Caro, A. (agosto, 2007). Fundamentos epistemológicos y metodológicos para un estudio científico de la publicidad. Pensar la publicidad, 1(1), 55-82.

7. CFSC. (2003). Escuchar... aprender... las voces comunitarias que promueven el cambio. Recuperado de http://www.communicationforsocialchange.org/pdf/cfsc_consortium_brochure_spanish.pdf

8. Chaparro, M. (enero-abril, 2013). La comunicación del desarrollo. Construcción de un imaginario perverso. Cuadernos de Comunicación e Innovación, (94), 2-10.

9. De Andrés, S. y González, R. (marzo, 2012). Comunicación inclusiva. Una experiencia en creación de campañas sobre discapacidad intelectual. Área abierta, 12(1), 1-18. 


\section{DISERTACIONES}

10. De Sousa, B. y Meneses, M. (eds.). (2014). Epistemologías del sur (perspectivas). Madrid: Akal.

11. Fueyo, A. (2002). De exóticos paraísos y miserias diversas. Publicidad y (re)construcción del imaginario colectivo sobre el Sur. Barcelona: Icaria.

12. Gumucio, A. (2001). Haciendo olas: historias de comunicación participativa para el cambio social. Nueva York: Fundación Rockefeller.

13. Gumucio, A. (agosto, 2004). El cuarto mosquetero: la comunicación para el cambio social. Investigación y Desarrollo, 12(1), 02-23.

14. Hallam, E. y Street, B. (eds.). (2000). Cultural Encounters: Representing Otherness. Sussex Studies in Cultural and Communication. Londres: Routledge.

15. Herzog, B. (septiembre-diciembre, 2011). Exclusión discursiva. Hacia un nuevo concepto de la exclusión social. Revista internacional de sociología, 69(3), 607-626.

16. Igartua, J. y Humanes, M. (2004). El método científico aplicado a la investigación en comunicación social. Barcelona: Incom.Uab.

17. Lafuente, M. y Faura, U. (febrero, 2012). Estudio de la vulnerabilidad a la exclusión social por comunidades autónomas en España (2005-2009). Investigaciones Regionales, 23, 105-124.

18. Marco, M. (abril, 2000). Consideraciones en torno al concepto de exclusión social. Acciones e investigaciones sociales, (11), 9-22.

19. Marí, V. (noviembre, 2013). Comunicación, desarrollo y cambio social en España: entre la institucionalización y la implosión del campo. Revista de Comunicación y Ciudadanía Digital, 2(2), 40-64.

20. Navarro, L. (octubre, 2009). El hacer y el decir como acciones propias de la libertad humana. Una mirada a la comunicación para el cambio social desde el pensamiento de Hannah Arendt. Revista de la Facultad de Comunicaciones de la Universidad de Antioquia, (21), 27-49.

21. Nos, E., Seguí-Cosme, S. y Rivas, A. (2008). Comunicación y construcción de paz. Barcelona: Icaria.

22. Rockefeller Foundation (1997). Communications and Social Change: Forging Strategies for the 21st Century. Recuperado de http://web.asc.upenn.edu/gerbner/Asset.aspx?assetID=1385

23. Romm, G. (julio, 1999). Social Exclusion, Solidarity and the Challenge of Globalization. International Journal of Social Welfare, 8(3), 166-174.

24. Ruiz de Olabuénaga, J. (1999). Metodología de la investigación cualitativa. Bilbao: Universidad de Deusto.

25. Sáiz, V. (2010). La solidaridad espacio de mediación de los sentimientos morales: análisis de la publicidad de las ONGD. (Tesis doctoral). Recuperado de http://goo.gl/BVUXjF

26. Seveso, E. (agosto, 2009). Imágenes de la diferencia. Construcción subjetiva, otredad y medios de comunicación. Fundamentos en humanidades, 1(19), 9-23.

27. Sierra, F. (2010). Capitalismo cognitivo y sociedad de la información. La deriva privatista de la UE. En S. Sel. (coord.). Políticas de comunicación en el capitalismo contemporáneo. (pp. 233-255). Buenos Aires: Clacso.

28. Silver, H. (1994). Social Exclusion and Social Solidarity: Three Paradigms. International Labour Review, 133, 531-578.

29. Subirats, J. (2005). Análisis de los factores de exclusión social. Bilbao: BBVA.

30. Tezanos, J. (1999). Tendencias en desigualdad social. Madrid: Sistema. 


\section{DISERTACIONES}

31. The World Bank. (2007). World Congress on Communication for Developmet. Recuperado de http://www. fao.org/docrep/010/ai143e/ai143e00.htm

32. Van Dijk, T. (junio, 2002). El análisis crítico del discurso y el pensamiento social. Athenea Digital, (1), 18-24.

33. Wimmer, R. y Dominik, J. (1996). La investigación científica de los medios de comunicación. Una introducción a sus métodos. Barcelona: Bosch.

34. Zebadúa, J. (junio, 2005). Imágenes distorsionadas, realidades adjetivadas. La comunicación y su papel actual como espacio de exclusión. Gazeta de antropología, 21(18). Recuperado de http://www.ugr. es/ pwlac/G21_18JuanPablo_Zebadua_Carboney.html 